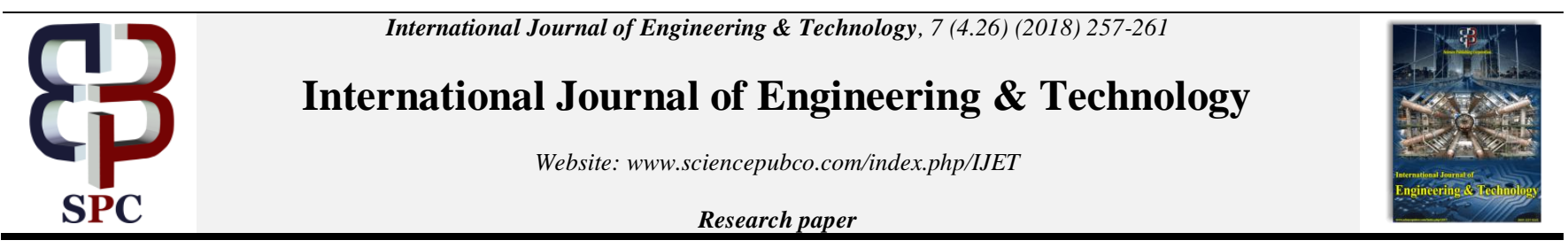

\title{
Biomorphic Silicon Carbide from Malaysian Hardwood
}

\author{
Noor Leha Abdul Rahman ${ }^{1 *}$, Koay Mei Hyie,$^{2}$ Anizah Kalam ${ }^{3}$, Fauziah Md Yusof ${ }^{4}$ \\ ${ }^{134}$ Faculty of Mechanical Engineering, Universiti Teknologi MARA, 40450 Shah Alam, Malaysia \\ ${ }^{2}$ Faculty of Mechanical Engineering, Universiti Teknologi MARA, 13500 Permatang Pauh, \\ Pulau Pinang, Malaysia \\ *Corresponding author E-mail;::noorleha3585@salam.uitm.edu.my
}

\begin{abstract}
Porous silicon carbide with mimicking the original microstructure of wood are prepared by pyrolysis and subsequently impregnated with silicon by silicon melt infiltration. The infiltration process was performed at $1500{ }^{\circ} \mathrm{C}$ for 3 hours holding times in inert atmosphere. Two types of wood were used as precursor which is Kapur and dark red Meranti. The morphology of resulting porous $\mathrm{SiC}$ have been investigated using scanning electron microscope (SEM/EDX) and X-ray diffraction (XRD) analysis. The density of the samples was characterized by Archimedes methods. The excess of silicon was removed by etching with the mixture of hydrofluoric and nitric acid. The flexural strength was tested by the three-point flexural method at room temperature.It has been shown that the final SiC for both precursors have similar density. The existence of $\mathrm{SiC}$ was proved by the XRD result, whereas EDX analysis of silicon content revealed that the formation of silicon carbide in dark red Meranti is higher than that of Kapur. The flexural strength and modulus of dark red Meranti samples were much higher than those of the kapur samples because of higher formation of silicon carbide in dark red Meranti.
\end{abstract}

Keywords: biomorphic SiC, Kapur, dark red Meranti, infiltration, flexure strength

\section{Introduction}

Wood waste is one of the most urgent because almost all of them were brought into the landfill of household waste. The major source of wood waste comes from commercial and residential activities. The construction and demolition of old building generate a significant amount of solid waste. It includes sawdust or wood scrap from sawmill and furniture factory, landscaping, lumber mills as well as branches or tree removed from the orchard The large amount of wood waste will sent to the landfill and end up with open burning. According to Zuni ,the estimated of solid waste in Malaysia in 2020 is 9092611 tons per year. As at present, landfill is the only method used for disposal solid waste in Malaysia and most of landfill sites are open dumping area [2][3]. These will contribute to the air pollution and other environmental problem. Considering wood based industry as one of the Malaysian's industry sources, this sector produces a significant environmental impact because these residues are totally wasted. This problem initiates the development of wood waste into the useful materials. Conversion of wood into biomorphic silicon carbide is one of the interesting research and potential solution because the availability and low cost of wood source thus reduced the processing cost.

Porous silicon carbide is one of the promising materials for high temperature applications due to its excellent strength, hardness and oxidation resistance. The use of natural materials such as wood, coconut, papers, bamboo as a biotemplate material have received more attention in the last decade[4][5]. The abundant, renewable, less expensive and environmentally friendly are the factors where wood was chosen as a precursor. In addition, the resultant silicon carbide inherits microstructure of original wood. This unique property can be used in varied applications including catalyst, liquid and gas separation, filters and catalyst support and automotive industry. The increasing demand in silicon carbide based natural materials or ecoceramic has attracted much interest many researchers in the field of biomorphic silicon carbide.

Wood is a solid material derived from woody plant which can be classified into hardwood and softwood. Hardwood composed of cellulose, hemicelllulose and lignin [6]. The existent of these three components forms an insoluble network, which is difficult to be separated. The only simple way to convert lignocellulosic materials is by pyrolysis. During pyrolysis, these three components decomposed into amorphous carbon which maintained their original wood structure. Pyrolysis temperature that are commonly applies is in the range of $500-900{ }^{\circ} \mathrm{C}[7][8]$.

A number of research have been done on converting woods into silicon carbide with different kinds of typical Mediterranean species such as pine ,Birch[10],beech [11], eucaplitus[12] and oak [13].Different approaches were developed for conversion of woods into $\mathrm{SiC}$ ceramic. The basic process for the formation of porous $\mathrm{SiC}$ is by transforming wood into carbon template and subsequently reacting this template with silicon. This has been carried out by liquid silicon infiltration [15] or by soaking cabon template into ethanol solution of tetraethoxysilane $\left[\mathrm{Si}\left(\mathrm{OC}_{2} \mathrm{H}_{5}\right)_{4}[13]\right.$ or $\mathrm{SiO}$ gas infiltration [16]. However, silicon melts infiltration methods has the best methods since the resulted sic have good mechanical properties [17].

The objective of this study is to evaluate the mechanical properties of silicon carbide from Malaysian species which is dark red Meranti (Shorea spp) and Kapur (Dryobalanop spp). This species were classified as light hardwood and medium hardwood respectively, and the classification of Malaysian Timber Industry is based on their wood density. Medium hardwood is extensively used for the production of furniture, cabinet and kitchen unit[18]. Kapur and dark red Meranti was converted into SiC by infiltration of molten silicon into carbon perform, which was fabricated from 
pyrolysis process. The infiltration was performed at 3 hours holding time in order prolong the formation of silicon carbide.

\section{Methodology}

\subsection{Materials and Methods}

Dark red Meranti and Kapur were selected as a precursor to fabricate $\mathrm{SiC}$ ceramic. The wood sample was first prepared by cutting into rectangular shape of $100 \mathrm{~mm} \times 25 \mathrm{~mm} \times 20 \mathrm{~mm}$. Then, the sample was oven dried for 24 hours at $110{ }^{\circ} \mathrm{C}$ to remove the moisture. The woods sample was then pyrolyzed in a tube furnace with an argon flow.

Two stages of heating were done to avoid cracking of samples. The first stage involved a heating to $500^{\circ} \mathrm{C}$ at $1{ }^{\circ} \mathrm{C} / \mathrm{min}$ for $30 \mathrm{~min}$ utes. The second stage involved a heating to $850{ }^{\circ} \mathrm{C}$ with $2{ }^{\circ} \mathrm{C} / \mathrm{min}$ and held for 1 hour. The pyrolyzed wood was then packed in excess silicon powders and heated up to $1500{ }^{\circ} \mathrm{C}$ for 1 to 5 hours holding times. Finally, Chemical etching with a solution of hydrofluoric (HF) and Nitric Acid (HNO) was used to remove excess silicon. Fig. 1 summarizes the processing scheme of manufacturing silicon carbide from wood.

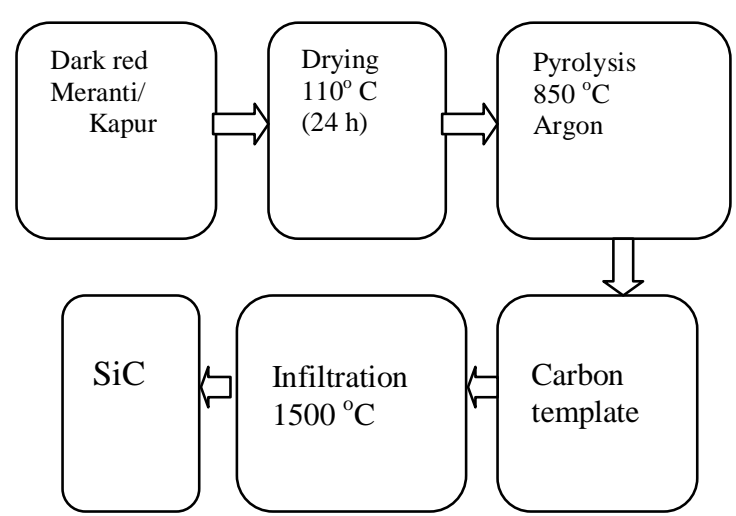

Fig. 1: Processing methods of manufacturing silicon carbide from wood

\subsection{Characterization}

Thermogravimetric analysis was performed by a thermal analyzer (Model Netzsch TG 209 F3) under flowing nitrogen gas at flow-

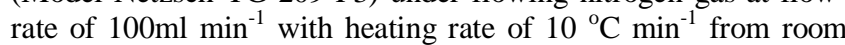
temperature to $1000^{\circ} \mathrm{C}$. Alumina powders was used as a reference sample to determine the mass loss during pyrolysis. Density was measured by Archimedes method (ASTM C373-88) whereas Scanning Electron Microscope (SEM-Hitachi S-2500) operated at $20 \mathrm{kV}$ and $20 \mathrm{~mA}$ was used for microstructure analysis. The phase composition was determined by X-ray Diffraction (XRD) on a RigakuUltima III) X-ray diffractometer using $\mathrm{Cu} \mathrm{K \alpha}$ radiation produced at $35 \mathrm{kV}$ and $20 \mathrm{~mA}$ and Energy-dispersive X-ray spectroscopy (EDX) with a detector attached to the same SEM .Three point flexural strength were performed using ASTM -C1161 configuration $B$ with inner $20 \mathrm{~mm}$ and $40 \mathrm{~mm}$ outer span with a 1 $\mathrm{mm} / \mathrm{min}$ crosshead speed.

\section{Results and Discussion}

\subsection{Silicon Carbide Formation}

Wood structure were pyrolyzed in argon atmosphere to obtain solid carbon perform. During pyrolysis, there are some shrinkage and weight loss occur on the dimension of wood which is about $60-70 \%$ of its volume and its depends on the variation of pore size, orientation as well as different percentage of wood compositions [5][19]. Decomposition of organic polymers in wood structures known as celluloce, hemicelluloses and lignin lead to the shrinkage and weight loss that left behind the only carbon structure.
The infiltration of carbon preform with liquid silicon involves packing of carbon preform in excess silicon powders and heating up to above melting temperatures of silicon. The conversion of carbon into silicon carbide can be expressed as

$C($ solid $)+\operatorname{Si}($ liquid $) \rightarrow \operatorname{SiC}($ solid $)$

During infiltration, some carbon preform was converted into $\mathrm{SiC}$ by filling up the pore with liquid silicon and few pores were not completely filled. The formation of $\mathrm{SiC}$ were from capillary effect and reactive wetting. The driving forces from both factor sled to the infiltration of silicon into small and large pores followed by reaction of carbon with liquid $\mathrm{Si}$. The formations of $\mathrm{SiC}$ layer occur very fast which was less than 2 seconds. The primary layer of $\mathrm{SiC}$ occurred at the surface of the pore structure. The existence of excess $\mathrm{Si}$ in the sample can be removed by leaching process with hydrofluoric acid and nitric acid according to:

$3 \mathrm{Si}+12 \mathrm{HF}+4 \mathrm{HNO}_{3} \rightarrow 3 \mathrm{SiF}_{4}+4 \mathrm{NO}+8 \mathrm{H}_{2} \mathrm{O}$

$\mathrm{SiO}_{2}(\mathrm{~s})+6 \mathrm{HF}(\mathrm{l}) \rightarrow \mathrm{H}_{2} \mathrm{SiF}_{6}(\mathrm{l})+2 \mathrm{H}_{2} \mathrm{O}(\mathrm{l})$

The final resulted $\mathrm{SiC}$ composed of crystalline $\mathrm{SiC}$ and unreacted carbon.

As can be seen from the Table 1 below, density of raw kapur is higher than of raw dark red meranti as kapur is classified in group medium hardwood instead of light hardwood for dark red meranti. Carbonization of wood by pyrolysis process will remove the moisture and also organic polymer content in original wood structure thus reduced the density of pyrolyzed carbon. The final resulted $\mathrm{SiC}$ from both wood precursors did not show a significant difference between them. Despite kapur having high density,the final resulted $\mathrm{SiC}$ almost similar to that dark red meranti which is 0.81 and 0.858 respectively. As the density of the resulted $\mathrm{SiC}$ is linear proportional to the density of pyrolyzed carbon[20][21].The formation of $\mathrm{SiC}$ from carbon perform not only dependent on density of carbon preform but also the porosity and the microstructure, such as anisotropic orientation and diameter of the tracheidal pore structures [22]

Table 1: Density of original, pyrolyzed and resulted siC for kapur and dark red meranti precursor

\begin{tabular}{|l|l|l|}
\hline $\begin{array}{l}\text { Density } \\
\text { g/cm }\end{array}$ & Kapur & Dark red meranti \\
\hline Raw & 0.819 & 0.778 \\
\hline Pyrolyzed & 0.671 & 0.583 \\
\hline SiC & 0.891 & 0.858 \\
\hline
\end{tabular}

\subsection{TGA}

Fig. 2 and Fig. 3 shows the TG and DTG analysis curves of kapur, dark red meranti in Argon atmosphere flow rate of $110 \mathrm{ml} / \mathrm{min}$ and $10^{\circ} \mathrm{C} / \mathrm{min}$ heating rate.Generally, the mechanism in the conversion of wood into carbon is quite similar to all three kinds of wood. However, some differences may exist due to differences in cell wall structure of different wood samples [15]. The TG curves show that the major decomposition of woods happened dramatically in a range of temperature from $275^{\circ} \mathrm{C}$ to $475{ }^{\circ} \mathrm{C}$. The maximum mass loss rate of Kapur is at temperature of 345 ,lower than of dark red Meranti which is at $360{ }^{\circ} \mathrm{C}$. At the end of pyrolysis process, the total residual mass left of Kapur and dark red Meranti $25.32 \%$ and $13.27 \%$ and $4.82 \%$ respectively. The differences in the inherent structures and chemical nature of the three components in each type of wood possibly account for the different in total mass residual left. The variation of the weight loss was related to differences in the types of chemical compounds, especially more weight loss occurred with the lower lignin content[23]. 


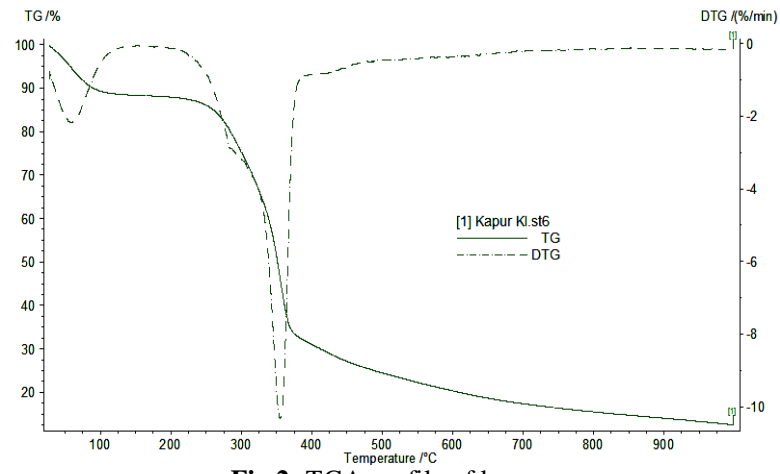

Fig 2: TGA profile of kapur

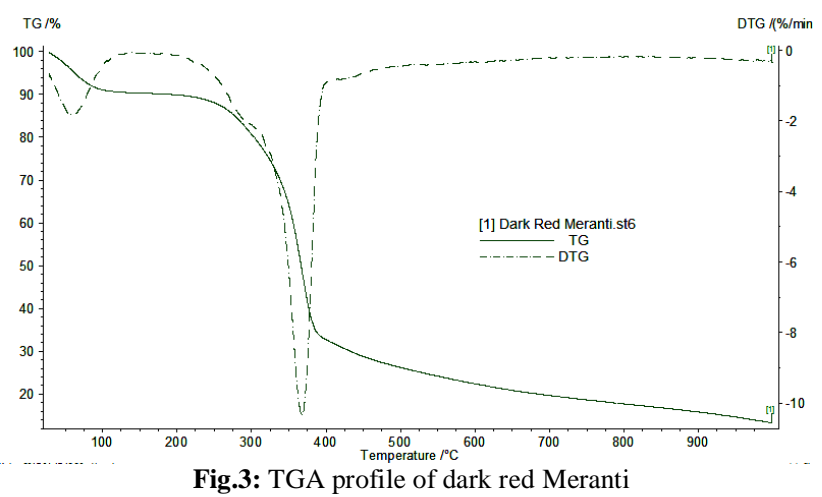

The temperature above $600^{\circ} \mathrm{C}$ was the stage where the graphitic carbon forming, which is necessary for infiltration process [24].Generally, the mechanism in the conversion of wood into carbon is quite similar to other kinds of wood. However, some differences may exist due to differences in cell wall structure of different wood samples [21].

\subsection{SEM}

The microstructure from carbon perform for kapur and dark red meranti obtained by pyrolysis process are shown in Fig.4 ( $a$ and $b$ ) respectively. It can be seen that the capillaries inside the solid framework of carbon template as the structure of the original wood template was retained.
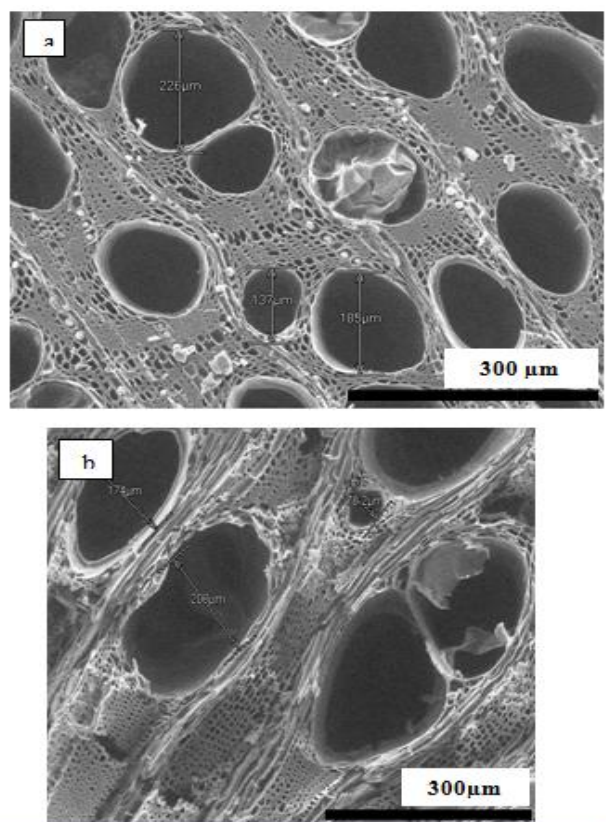

Fig 4: SEM micrograph of pyrolized wood from (a) Kapur and (b) dark red Meranti
Different kinds of woods will have a different shapes and sizes of pores. Kapur has two kind of pore structure which is small and large pore. Its pore sizes is approximately between $150 \mu \mathrm{m}$ $230 \mu \mathrm{m}$. Dark red Meranti however has majority large pore structure with some smaller pores. Their pore sizes are between $70 \mu \mathrm{m}$ to $370 \mu \mathrm{m}$.
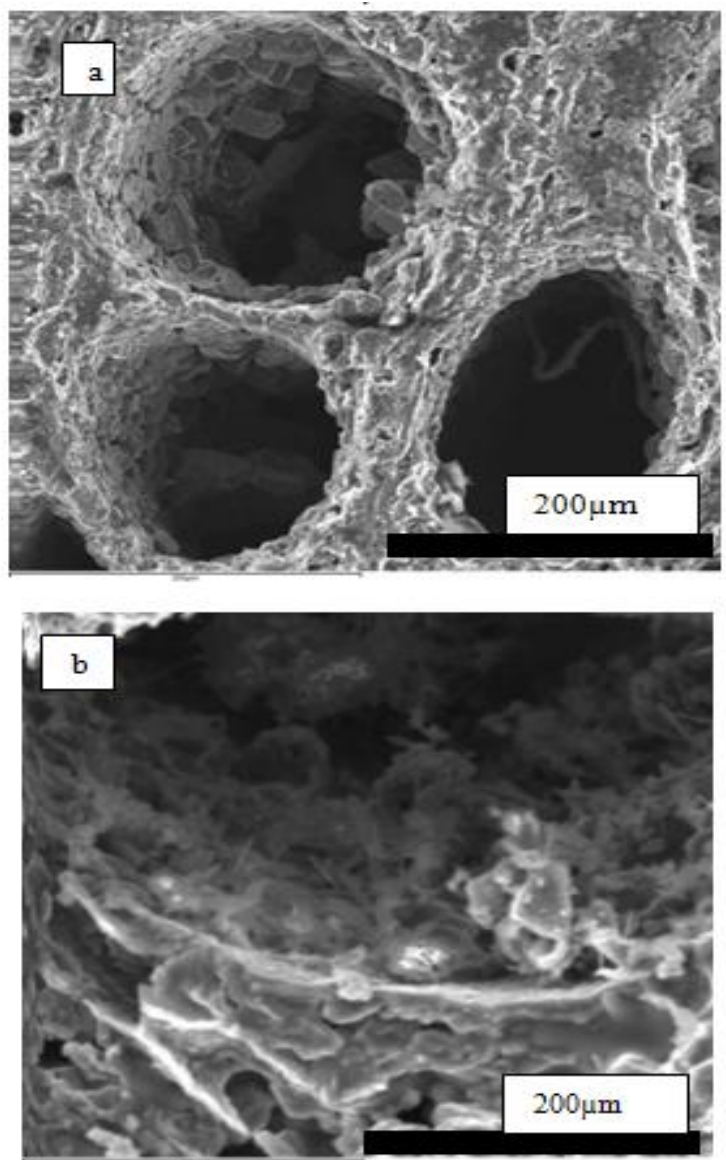

Fig. 5: SEM micrograph of Sic from (a) Kapur and (b) dark red Meranti

These open structures in the initial carbon preform helps in the conversion of carbon to $\mathrm{SiC}$ by facilitating $\mathrm{Si}$ vapors to pass into and through the pores and to react with the carbon.

The SEM images of resulted porous SiC are shown in Figure 3(ab). It can be seen that the structure of the original wood template was retained. The formation of crystalline $\mathrm{Si}$ at the surface and pore walls are clearly visible. The resulted $\mathrm{SiC}$ filled some pores and covered up the whole surface and few of $\mathrm{SiC}$ formed and filled at pore wall. However, there are some of pore does not filled by molten silicon. This is because the capillary effect is higher in smaller pores. The liquid silicon from the larger pore was extracted into small pores until the pressure equilibrium is reached [11] as can be seen in Figure 2(d).

The infiltration of Si through pore can be shown in the elemental mapping as shown in Fig 6 . The green colour is corresponding to silicon while red colour is corresponding to carbon element. It can be observed that the green colour which correspond to silicon are more in the pore walls which prove that the formation of silicon carbide occur in the pore structure .It is also evident how the $\mathrm{SiC}$ phase mimics the precursor microstructure.

It is concluded that the pore size is one of the important factor for optimum infiltration to occur. If pore diameter is too small, the $\mathrm{SiC}$ formed at the surface could block and restricted further infiltration process inside the pore walls. Otherwise too large pore could leave unreacted carbon as $\mathrm{SiC}$ not fully converted [25].Therefore, the pore size should be ideal for optimum reaction to occur. Besides, another factor that could be considered in $\mathrm{Si}$ infiltration included contact angle and surface tension [26]. 


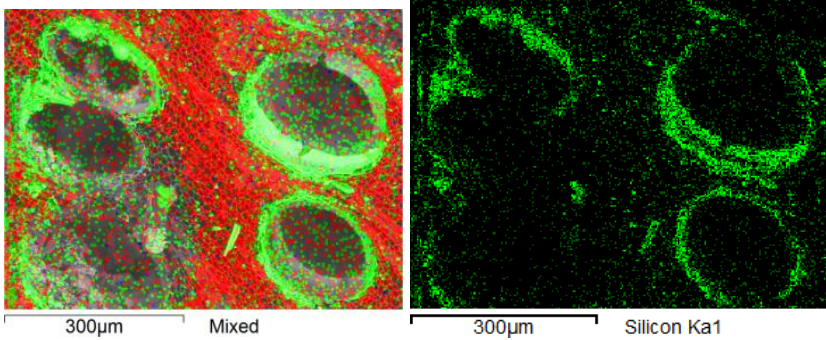

Fig6: Elemental maping of silicon carbide (a) silicon (green) and carbon(red) element (b) silicon element (green)

\subsection{XRD}

Fig.7 shows the XRD patterns of carbon preform and resulting $\mathrm{SiC}$. It can be seen that carbon is amorphous with a broad peaks at around $22^{\circ}$ and $44^{\circ}$ suggesting that both pyrolyzed kapur and dark red meranti are amorphous. The major crystalline phase is $\mathrm{SiC}$ at $2 \theta=35.6^{\circ}, 41.4^{\circ}, 59.9^{\circ}$ and $75.5^{\circ}$.It is apparent that the intensity of the XRD peaks corresponding to kapur is significantly higher than peaks correspond to $\mathrm{SiC}$ derived Dark red meranti. the peaks correspond to carbon amorphous clearly disappeared. High intensity in $\mathrm{SiC}$ derived kapur shows the samples has high crystall structure and this in agreement with SEM in Fig.5 (a). There is no detectable residual silicon peak which as residue $\mathrm{Si}$ was remove away by etching process [27].

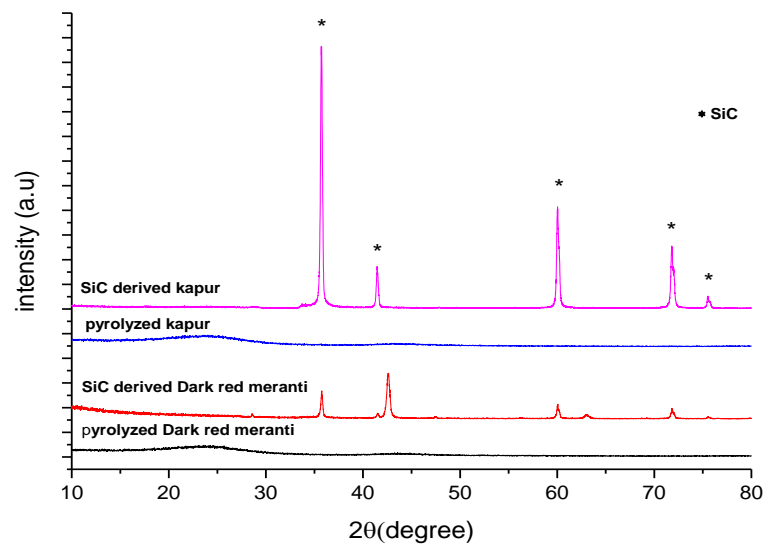

Fig7: XRD pettern of pyrolized carbon and resulting siC at 3 hours holding time

\subsection{Mechanical Properties}

Mechanical properties (flexural strength,and Young's modulus) of biomorphic SiCs were determined using three- point flexural tests at room temperature. The fracture surfaces of the $\mathrm{SiC}$ were found to be flat and smooth, characteristic of brittle fracture. It was found that the flexural strength of $\mathrm{SiC}$ derived dark red meranti is higher than $\mathrm{SiC}$ derived kapur. The higher flexural strength and modulus values of the infiltrated dark red meranti preform are most likely attributable to the presence of a greater amount of $\mathrm{SiC}$ phase as the $\mathrm{Si}$ content is 48.93 w.t $\%$, and a lesser amount of $\mathrm{Si}$ in $\mathrm{SiC}$ derived kapur which is 44.98 w.t $\%$. The mechanical properties of the wood derived biomorphic SiC composites not only depend on he density but also the porosity and the microstructure, such as anisotropic orientation and diameter of the tracheidal pore structures [22] .

Table 2: Mechanical properties of SiC derived Kapur and dark red Meranti

\begin{tabular}{|l|l|l|}
\hline $\mathrm{SiC}$ & $\begin{array}{l}\text { Flexural strength } \\
(\mathbf{M P a})\end{array}$ & $\begin{array}{l}\text { Elastic modulus } \\
(\mathbf{G P a})\end{array}$ \\
\hline Kapur & 33.33 & 20.83 \\
\hline Dark red Meranti & 53.03 & 32.63 \\
\hline
\end{tabular}

\section{Conclusion}

Biomorphic $\mathrm{SiC}$ ceramics have been successfully pre-pared using silicon melt infiltration method using two types of precursor;kapur from medium hard wood and dark red meranti from light hard wood. The resulting porous microstructure mimics the original wood microstructure and is made up of a $\mathrm{SiC}$ network filled with $\mathrm{Si}$. SEM micrograph reveals that the formation if $\mathrm{SiC}$ are mostly occur in the pore walls of wood structure. Dark red Meranti show a high flexural strength compared to Kapur which is 53.33 MPa, indicating that the formation of silicon carbide in wood structure not only depends on the original wood density as the final density for both precursor almost similar.

\section{Acknowledgement}

The authors would like to thank Mr.Rahimi for the use of SEM Instrument and Mr Hazrol for XRD at the Mechanical Engineering Faculti, UiTM, the author also would like to gratefully acknowlegde to Mr Amin from Faculty of Chemical Engineering, UiTM for three point flexural instrument.

\section{References}

[1] zaini md Nor, "solid waste management in malaysia," in International Conference On Urban Development And Management, 2010, http://www.swcorp.gov.my/docfile/kertastaklimat/SWMPresentationOktober.pdf

[2] L. A. Manaf, M. Armi, A. Samah, N. Ilyana, and M. Zukki, "Municipal solid waste management in Malaysia: Practices and challenges," vol. 29, pp. 2902-2906, 2009.

[3] Y. Moh and L. A. Manaf, "Resources, Conservation and Recycling Solid waste management transformation and future challenges of source separation and recycling practice in Malaysia," "Resources, Conserv. Recycl., vol. 116, pp. 1-14, 2017.

[4] O. P. Chakrabarti, H. S. Maiti, and R. Majumdar, "Biomimetic synthesis of cellular SiC based ceramics from plant precursor," Bull. Mater. Sci., vol. 27, no. 5, pp. 467-470, 2004.

[5] P. Greil, "Biomorphous ceramics from lignocellulosics," J. Eur. Ceram. Soc., vol. 21, no. 2, pp. 105-118, 2001.

[6] T. Conners, "Introduction to Wood Structure and Characteristics," 1914.

[7] B. L. R. A, "Carbonization Of Wood At $400{ }^{\circ}$ C For Composite Materials," state universisty of new york, 2011.

[8] C. E. B. and D. C. NAGLE, "Wood monoliths-characterization," vol. 35 , no. 2 , pp. 267-273, 1997.

[9] J. Locs, L. Berzina-Cimdina, a. Zhurinsh, and D. Loca, "Effect of processing on the microstructure and crystalline phase composition of wood derived porous SiC ceramics," J. Eur. Ceram. Soc., vol. 31 no. 1-2, pp. 183-188, Jan. 2011.

[10] Z. L. Yan, J. Liu, J. C. Zhang, T. Ma, and Z. C. Li, "Comparative Study of Biomorphic Silicon/Silicon Carbide Ceramic from Birch and Compressed Birch," Key Eng. Mater., vol. 434-435, pp. 609612, Mar. 2010.

[11] F. M. Varela-Feria, J. Ramírez-Rico, A. R. de Arellano-López, J. Martínez-Fernández, and M. Singh, "Reaction-formation mechanisms and microstructure evolution of biomorphic SiC," J. Mater. Sci., vol. 43, no. 3, pp. 933-941, 2008.

[12] M. Presas, J. Y. Pastor, J. Llorca, a. R. A. López, J. M. Fernández, and R. Sepúlveda, "Microstructure and fracture properties of biomorphic SiC," Int. J. Refract. Met. Hard Mater., vol. 24, no. 1-2, pp. 49-54, 2006.

[13] J. Qian, J. Wang, and Z. Jin, "Preparation of biomorphic SiC ceramic by carbothermal reduction of oak wood charcoal," Mater. Sci. Eng. A, vol. 371, no. 1-2, pp. 229-235, Apr. 2004.

[14] P. Greil, T. Lifka, and A. Kaindl, "Biomorphic cellular silicon carbide ceramics from wood: II. Mechanical properties,” J. Eur. Ceram. Soc., vol. 18, no. 14, pp. 1975-1983, 1998.

[15] H. S. Park, J. J. Jang, K. H. Lee, K. H. Lim, S. B. Park, Y. C. Kim, and S. H. Hong, "Effects of microstructure on flexural strength of biomorphic $\mathrm{C} / \mathrm{SiC}$ composites," Int. J. Fract., vol. 151, no. 2, pp. 233-245, 2008. 
[16] E. Vogli, H. Sieber, and P. Greil, "Biomorphic SiC-ceramic prepared by Si-vapor phase infiltration of wood," J. Eur. Ceram. Soc. vol. 22, no. 14-15, pp. 2663-2668, 2002.

[17] S. D. W. and P. S.s, "Silicon/Silicon Carbide composites fabricated by infiltration of a Silicon Melt into Charcoal," J.Am.Ceram.Soc, vol. 82, 1999.

[18] P. . B. Menon, structure \& Indentification of Malayan wood. fores research institut malaysia, 1971.

[19] C. E. Byrne and D. C. Nagle, "Carbonization of wood for advancedmaterials applications," Carbon N. Y., vol. 35, no. 2, pp. 259-266, 1997.

[20] F. . Varela-Feria, J. Martínez-Fernández, a. . de Arellano-López, and M. Singh, "Low density biomorphic silicon carbide: microstructure and mechanical properties," J. Eur. Ceram. Soc., vol. 22, no. 14-15, pp. 2719-2725, 2002.

[21] N. R. Calderon, M. Martinez-Escandell, J. Narciso, and F. Rodríguez-Reinoso, "The role of carbon biotemplate density in mechanical properties of biomorphic SiC," J. Eur. Ceram. Soc., vol. 29 no. 3, pp. 465-472, Feb. 2009.

[22] H. S. Park, J. J. Jang, K. H. Lee, K. H. Lim, S. B. Park, Y. C. Kim, and S. H. Hong, "Effects of microstructure on flexural strength of biomorphic C / SiC composites," pp. 233-245, 2008

[23] A. Fernandez, A. Saffe, R. Pereyra, G. Mazza, and R. Rodriguez, "Kinetic study of regional agro-industrial wastes pyrolysis using non-isothermal TGA analysis," Appl. Therm. Eng., vol. 106, pp. 1157-1164, 2016.

[24] "Production And Characterization Of Carbon StructureS," 2008.

[25] J. C. Margiotta, "Study Of Silicon Carbide Formation By Liquid Silicon Infiltration Of Porous Carbon Structures," 2009.

[26] A. Esther and S. Childers, "Processing, Microstructure, and Mechanical Properties of Interpenetrating Biomorphic Graphite / Copper Composites," no. August, 2014

[27] C. Torres-Raya, D. Hernandez-Maldonado, J. Ramirez-Rico, C. Garcia-Gañan, A. R. de Arellano-Lopez, and J. Martinez-Fernandez, "Fabrication, chemical etching, and compressive strength of porous biomimetic SiC for medical implants," J. Mater. Res., vol. 23, no. 12, pp. 3247-3254, 2008. 